\title{
Erratum to: Signaling Pathways Involved in 1-Octen-3-ol-Mediated Neurotoxicity in Drosophila melanogaster: Implication in Parkinson's Disease
}

Arati A. Inamdar $\cdot$ Prakash Masurekar •

Muhammad Hossain · Jason R. Richardson •

Joan W. Bennett

Published online: 4 October 2013

(C) Springer Science+Business Media New York 2013

Erratum to: Neurotox Res

DOI 10.1007/s12640-013-9418-z

The authors would like to add an acknowledgment for grant support:

Acknowledgments The study was supported by Rutgers University Research Funds R01ES015991, P30ES005022, and R21NS072097.

The online version of the original article can be found under doi:10.1007/s12640-013-9418-z.

A. A. Inamdar $(\bowtie) \cdot$ P. Masurekar $\cdot$ J. W. Bennett

Department of Plant Biology and Pathology, Rutgers, The State

University of New Jersey, New Brunswick, NJ 08901, USA

e-mail: inamdar@rci.rutgers.edu

M. Hossain · J. R. Richardson

Environmental and Occupational Health Sciences Institute,

Rutgers, The State University of New Jersey, Piscataway,

NJ 08854, USA 